\title{
A Low Clozapine Dose Improved Refractory Tardive Dystonia without Exacerbating Psychiatric Symptoms: A Case Report
}

\author{
Naomichi Okamoto $\mathbb{D D}^{\prime}$ \\ Yuki Konishi' \\ Hirofumi Tesen' \\ Atsuko Ikenouchi (iD ${ }^{1,2}$ \\ Reiji Yoshimura' \\ 'Department of Psychiatry, University of \\ Occupational and Environmental Health \\ Kitakyushu, Fukuoka, 8078555, Japan; \\ ${ }^{2}$ Medical Center for Dementia, University \\ Hospital, University of Occupational and \\ Environmental Health Kitakyushu, \\ Fukuoka, 8078555, Japan
}

\begin{abstract}
Clozapine is recommended for patients with schizophrenia and tardive dystonia (TD); however, the appropriate dose remains unclear. In this case, a low dose (150 mg/day) of clozapine improved refractory TD and further ameliorated psychiatric symptoms. Herein, we report on a 41-year-old female with schizophrenia and TD who was treated with a low clozapine dose. After eight weeks of continuous clozapine at $150 \mathrm{mg} /$ day $(16$ weeks after clozapine initiation), her TD dramatically improved, and her psychiatric symptoms were relieved. Low clozapine doses could ameliorate refractory TD. However, this effect might require up to several weeks. Clinicians should be patient unless they consider it better to increase the clozapine dose.
\end{abstract}

Keywords: clozapine, tardive dystonia, schizophrenia

\section{Introduction}

Tardive dystonia (TD) occurs after exposure to antipsychotic drugs. Dopamine receptor hypersensitivity induced by antipsychotic drugs might be related to TD, but the pathophysiology of TD is complex and remains unknown. ${ }^{1}$

A number of drugs have been used for the management of TD, but so far, no effective or standard treatment has been established. Levodopa, anticholinergic, clonazepam, or quetiapine were reported as useful. ${ }^{2-4}$ Further, anecdotal reports have shown clozapine to improve TD. ${ }^{5}$ However, another report demonstrated that clozapine caused Pisa syndrome, a rare type of $\mathrm{TD}^{6}{ }^{6}$ To date, the efficacy of clozapine for TD remains controversial.

Herein, we report on a case of schizophrenia with refractory TD, where a low dose of clozapine was effective to treat refractory TD without worsening psychosis.

\section{Case Presentation}

A 41-year-old Japanese woman with schizophrenia was admitted to our university hospital. Her initial symptoms were psychomotor agitation, silly smile, delusion, and auditory hallucinations, including loud and strange voices, which started when she was 31 years old. She was diagnosed with schizophrenia and first received olanzapine $10 \mathrm{mg} /$ day. Thereafter, her psychiatric symptoms were relieved so the dose was maintained. At 38 years old, she noticed trunk twisting and jerking in her left upper extremity. Gradually, her neurological symptoms worsened. Owing to these symptoms, she had to give up her job in a fruit store. She consulted with an
Correspondence: Reiji Yoshimura Department of Psychiatry, University of Occupational and Environmental Health Kitakyushu, Fukuoka 8078555, Japan Tel +81936917253

Email yoshi62I@med.uoeh-u.ac.jp 
orthopedic surgeon and neurologist, but no organic or neurological abnormalities were noted. Consequently, she was diagnosed with olanzapine-induced TD, and the olanzapine $10 \mathrm{mg}$ /day was gradually tapered off. Meanwhile, her psychotic symptoms, such as auditory hallucinations, delusions, restlessness, and psychomotor agitation, reemerged. She was started on quetiapine $600 \mathrm{mg} /$ day and clonazepam $1.5 \mathrm{mg} /$ day, but her psychotic symptoms persisted without ameliorating her TD. Quetiapine was increased to $750 \mathrm{mg}$, and aripiprazole $24 \mathrm{mg}$ was added as well. Then, her psychotic symptoms gradually improved, but did not completely disappear, while her TD persisted and even worsened. As a result, she experienced great difficulties in daily living. Her score on the Drug-induced Extrapyramidal Symptoms Scale (DIEPSS) was 13 points, and her score on the Positive and Negative Syndrome Scale (PANSS) was 74. Hematological and biochemical examinations as well as thyroid function were normal. Her brain computed tomography scan showed no abnormal initial findings. Quetiapine and aripiprazole were tapered off, and clozapine was introduced, which was gradually increased to $200 \mathrm{mg}$ /day by week four. Since the somnolence occurred, the dose was reduced to $150 \mathrm{mg}$ after eight weeks. During this period, no changes in TD or psychiatric symptoms were noted. A situation that remained unchanged until after eight weeks of clozapine $150 \mathrm{mg}$ /day (16 weeks after starting clozapine) when her TD dramatically improved, and her psychiatric symptoms were relieved. Further, her DIEPSS and PANSS scores decreased to 3 and 66 points, respectively, as shown in Table 1. No side effects associated with clozapine were observed. Presently, she is aiming to get back to work.

The research protocol was approved by the Ethics Committee of the University of Occupational and Environmental Health. Written informed consent was obtained from the patient for publication of this case report.

\section{Discussion}

We present a case of schizophrenia with refractory TD. A low clozapine dose $(150 \mathrm{mg} /$ day $)$ ameliorated refractory TD symptoms and improved psychiatric symptoms. Clozapine is recommended for patients with schizophrenia and TD, but the appropriate dose remains to be elucidated, ${ }^{7}$ performed a review of articles in the PubMed database. The authors found 15 trials and 28 case series/case reports describing the use of clozapine in
Table I Change of PANSS and DIEPSS Scores in the Reported Case

\begin{tabular}{|l|l|l|l|l|}
\hline & $\mathbf{0}$ Week & $\mathbf{4}$ Weeks & $\mathbf{8}$ Weeks & $\mathbf{1 6}$ Weeks \\
\hline Dose of clozapine & 0 & $200 \mathrm{mg}$ & $150 \mathrm{mg} / \mathrm{day}$ & $150 \mathrm{mg} /$ day \\
DIEPSS Total & 13 & 13 & 13 & 3 \\
Gait & 3 & 3 & 3 & 1 \\
Bradykinesia & 1 & 1 & 1 & 0 \\
Sialorrhea & 0 & 0 & 0 & 0 \\
Muscle rigidity & 1 & 1 & 1 & 0 \\
Tremor & 2 & 2 & 2 & 1 \\
Akathisia & 0 & 0 & 0 & 0 \\
Dystonia & 3 & 3 & 3 & 0 \\
Dyskinesia & 0 & 0 & 0 & 0 \\
Overall severity & 3 & 3 & 3 & 1 \\
PANSS Total & 74 & 74 & 74 & 66 \\
Positive Total & 17 & 17 & 17 & 14 \\
Negative Total & 14 & 14 & 14 & 14 \\
General Total & 43 & 43 & 43 & 38 \\
\hline
\end{tabular}

Abbreviations: DIEPSS, Drug-induced Extrapyramidal Symptoms Scale; PANSS, Positive and Negative Syndrome Scale.

Tardive syndrome, including TD. Most reports showed that clozapine was beneficial for patients with Tardive syndrome in the dose range between 200 and $300 \mathrm{mg} /$ day and that the effects were observed within 4-12 weeks of clozapine initiation. Improvement in TD symptoms with clozapine is due to clozapine's low affinity for dopamine receptors, ${ }^{8}$ which might correlate with less extrapyramidal symptoms than that with other antipsychotic drugs. ${ }^{9}$ If this were true, a low dose might be better for TD patients. However, previous studies have demonstrated a clozapine dose-dependent improvement in dystonia, ${ }^{10}$ and relapse after clozapine discontinuation. ${ }^{11}$ If these findings are taken into consideration, the mechanism cannot solely be based on its low affinity for dopamine receptors. Antipsychotic drugs should generally be initiated at low doses, and gradually increase considering their efficacies and side effects. A low dose would be ideal to prevent side effects because the patients must take the drugs for long periods. Our patient responded to a low clozapine dose $<200 \mathrm{mg}$ /day, similar to that in most previous reports, and the time to TD improvement was eight weeks, also in accordance with a previous report. A recent systematic review $^{12}$ for clozapine and tardive dyskinesia with schizophrenia suggested that the minimum required dose and effect of withdrawal requires further investigation. We should also consider the improvement might be due to the discontinuation of the combination of quetiapine and aripiprazole as an alternative explanation. 
In conclusion, we reported that a low clozapine dose ameliorated refractory TD and improved psychiatric symptoms. The present case indicates that when treating schizophrenia patients with TD, clozapine should be initiated at a low dose and be gradually increased until reaching its effective dose, which may take several weeks. Thus, clinicians should be patient unless it is easy to increase the dose of clozapine.

\section{Abbreviations}

DIEPSS, Drug-induced Extrapyramidal Symptoms Scale; PANSS, Positive and Negative Syndrome Scale; TD, tardive dystonia.

\section{Data Sharing Statement}

All data generated or analyzed during this study are included in this published article.

\section{Ethics Approval and Consent to Participate}

The research protocol was approved by the Ethics Committee of the University of Occupational and Environmental Health. Written informed consent was obtained from the patient for publication of this case report.

\section{Author Contributions}

All authors made substantial contributions to conception and design, acquisition of data, or analysis and interpretation of data; took part in drafting the article or revising it critically for important intellectual content; agreed to submit to the current journal; gave final approval of the version to be published; and agree to be accountable for all aspects of the work.

\section{Funding}

This research did not receive any specific grant from funding agencies in the public, commercial, or not-forprofit sectors.

\section{Disclosure}

The authors report no conflicts of interest in this work.

\section{References}

1. Albanese A, Di Giovanni M, Lalli S. Dystonia: diagnosis and management. Eur J Neurol. 2019;26(1):5-17. doi:10.1111/ene.13762

2. Burke RE, Fahn S, Marsden CD. Torsion dystonia: a double-blind, prospective trial of high-dosage trihexyphenidyl. Neurology. 1986;36 (2):160-164. doi:10.1212/wnl.36.2.160

3. Gourzis P, Skokou M, Soubasi E, Katrivanou A, Polychronopoulos P Treatment of tardive dystonia induced by antipsychotics, old and new. Clin Neuropharmacol. 2015;38(4):121-126. doi:10.1097/ WNF.0000000000000086

4. Nutt JG, Nygaard TG. Response to levodopa treatment in dopa-responsive dystonia. Arch Neurol. 2001;58(6):905-910.

5. Joe S, Park J, Lim J, Park C, Ahn J. Remission of irreversible aripiprazole-induced tardive dystonia with clozapine: a case report. BMC Psychiatry. 2015;15:253. doi:10.1186/s12888-015-0644-1

6. Suresh Kumar PN, Gopalakrishnan A. Clozapine-associated Pisa syndrome: a rare type of tardive dystonia. Indian J Psychiatry. 2017;59 (3):390-391. doi:10.4103/psychiatry.IndianJPsychiatry_308_16

7. Hazari N, Kate N, Grover S. Clozapine and tardive movement disorders: a review. Asian J Psychiatr. 2013;6(6):439-451. doi:10.1016/ j.ajp.2013.08.067

8. Kapur S, Seeman P. Does fast dissociation from the dopamine d(2) receptor explain the action of atypical antipsychotics?: a new hypothesis. Am J Psychiatry. 2001;158(3):360-369. doi:10.1176/ appi.ajp.158.3.360

9. Divac N, Prostran M, Jakovcevski I, Cerovac N. Second-generation antipsychotics and extrapyramidal adverse effects. BioMed Res Int. 2014;2014:656370. doi:10.1155/2014/656370

10. Lieberman JA, Saltz BL, Johns CA, Pollack S, Borenstein M, Kane J. The effects of clozapine on tardive dyskinesia. $\mathrm{Br} J$ Psychiatry. 1991;158:503-510. doi:10.1192/bjp.158.4.503

11. Van Harten PN, Kampuis DJ, Matroos GE. Use of clozapine in tardive dystonia. Prog Neuro-Psychopharmacol Biol Psychiatry. 1996;20:263-274. doi:10.1016/0278-5846(95)00309-6

12. Pardis P, Remington G, Panda R, Lemez M, Agid O. Clozapine and tardive dyskinesia in patients with schizophrenia: a systematic review. J Psychopharmacol. 2019;33(10):1187-1198. doi:10.1177/ 0269881119862535

\section{Publish your work in this journal}

The International Medical Case Reports Journal is an international, peer-reviewed open-access journal publishing original case reports from all medical specialties. Previously unpublished medical posters are also accepted relating to any area of clinical or preclinical science. Submissions should not normally exceed 2,000 words or 4 published pages including figures, diagrams and references. The manuscript management system is completely online and includes a very quick and fair peer-review system, which is all easy to use. Visit http://www.dovepress.com/testimonials.php to read real quotes from published authors. 